\title{
Knowledge affecting foot-and-mouth disease vaccination behavior: traditional dairy farmers in the dry zone of Sri Lanka
}

\author{
Mohamed Jiffry Athambawa ${ }^{1} \cdot$ Satoko Kubota ${ }^{2} \cdot$ Hiroichi Kono ${ }^{2}$ \\ Received: 26 May 2020 / Accepted: 3 December 2020 / Published online: 7January 2021 \\ (C) The Author(s), under exclusive licence to Springer Nature B.V. part of Springer Nature 2021
}

\begin{abstract}
The aim of this study was to identify social and farm factors influencing the knowledge of foot-and-mouth disease (FMD), factors influencing participation in FMD vaccination, and vaccination coverage. The study was conducted with 180 traditional dairy farmers who were engaged in cattle and buffalo farming located in three veterinary ranges of the Ampara district in the eastern province of Sri Lanka, during September and October 2019. The probit and tobit regression models were applied to determine the factors. On an average, the scores for knowledge of FMD and hygiene management were calculated as $54.5 \%$ and $49.2 \%$, respectively. Farmers' knowledge of FMD was strongly associated with gender, level of education, and participation in the farmer training program $(p<0.01)$. The vaccination behavior was enhanced significantly by the number of animals, farming experience, knowledge of FMD score $(p<0.05)$, and hygiene management score $(p<0.1)$. It was revealed that social and farm factors contributed to the knowledge of FMD and vaccination behavior. Therefore, we recommend that the livestock educational training program will motivate better participation in the FMD control plan in Sri Lanka.
\end{abstract}

Keywords Foot-and-mouth disease $\cdot$ Knowledge $\cdot$ Hygiene management $\cdot$ Social factors $\cdot$ Vaccination behavior

\section{Introduction}

Foot-and-mouth disease (FMD) is one of the most economically important, highly contagious transboundary animal disease (TAD) of cloven-hoofed animals (Knight-Jones and Rushton 2013; OIE 2019). FMD is still widespread worldwide. It is prevalent in large parts of Africa, Middle East, and Asia, and countries that are free of FMD remain under the constant threat of incursion (FAO 2012). While the majority of FMD outbreaks occur in developing countries where veterinary capacities are minimum, the continuing epidemic of FMD has been described as a failure of the global food security system (Rushton 2009; Winsdor 2011). In Southeast

Hiroichi Kono

kono@obihiro.ac.jp

1 Doctoral Program of Animal Science and Agriculture, Obihiro University of Agriculture and Veterinary Medicine, Nishi 2-11, Inada-cho, Obihiro, Hokkaido 080-8555, Japan

2 Department of Agro-environmental Science, Division of Agricultural Economics, Obihiro University of Agriculture and Veterinary Medicine, Nishi 2-11, Inada-cho, Obihiro, Hokkaido 080-8555, Japan
Asia, the inclusion of FMD vaccination activities in FMD control and eradication programs is evident in Indonesia and the Philippines (Winsdor et al. 2011). FMD has a long history and was officially reported in 1900 in Sri Lanka (Sturgess 1900). This disease had assumed an epidemic in 6 years and had devastated the cattle and buffaloes in all provinces many times in the past (Fernando 1969).

The accepted control strategies available for FMD are stamping out, tracing outbreaks, legislation, quarantine, movement control, vaccination, import and export regulations, and zoo sanitary measures (Kodituwakku 2000). Successful vaccination programs prevent major epidemics of an infectious disease by generating herd immunity. Although FMD vaccination has been carried out every year, low vaccination coverage has caused this disease to rise to epidemic proportions (Fernando 1969). A socio-economic study in the Indian Punjab found that the educational level of farmers could be correlated with the likelihood of FMD outbreaks, and this could be linked to the fact that educated farmers were more likely to seek professional advice and vaccinate their animals regularly (Saini et al. 1992).

The FMD outbreaks would be high due to poor vaccination coverage, thereby resulting in enormous economic losses to livestock (Kodituwakku 2000). Farmers' knowledge about the 
disease is very important for an effective control program (Martin et al. 1994). Improving farmers' knowledge to differentiate FMD from other diseases and ensure prompt reporting of any suspicion of FMD as well as prompt restricting of movement of animals is a critical activity for an effective FMD response effort (Goswami and Sagar 1996). Farmers' behavior is strongly affected by their knowledge and attitudes (Dernburg et al. 2007).

In the last 10 years, FMD outbreaks were reported in the country, particularly in the dry zone of the eastern province among traditional dairy farming systems in small and large herd populations. Circulation of the FMD virus $\mathrm{O}$ type was confirmed in Sri Lanka (Gunasekera and Fernando 1980). According to the FMD control policy, the FMD mass vaccination program is implemented each year with the coordination of government veterinary offices in nine provinces in Sri Lanka; however, the FMD outbreak continues and the animal becomes clinically or subclinically affected. FMD vaccinations have been carried out in earmarked location in Sri Lanka. The number of target vaccines for FMD was 0.90 million and achieved 0.85 million in year 2019 (DAPH 2019). The Progressive Control Pathway (PCP) for FMD has been developed to assist and facilitate FMD endemic countries to progressively reduce the impact of disease and extend virus circulation (FAO 2018a). Cattle owners engage in low FMD vaccinations in different management systems. Farmers' FMD knowledge and vaccination behavior are poorly described. Therefore, we explored the gaps in knowledge of FMD, vaccination behavior, and the biosecurity and hygiene management practices that are necessary for control strategy in the socioeconomic consequences of FMD in Sri Lanka.

The objectives of this study were (1) to evaluate the social and farm factors influencing the knowledge of FMD, (2) to clarify the factors influencing participation in FMD vaccination and vaccination coverage, and (3) to ascertain farmers' motivation to participate in the extension program on animal disease control. This information is important for policymakers, livestock stakeholders, and small- and large-scale traditional farmers, where vaccination and management interventions are expected to be delivered by veterinary ranges providing effective and sustainable FMD control in Sri Lanka.

\section{Materials and methods}

\section{Study area}

Sri Lanka follows a diverse socio-cultural tradition. There are different farming management practices, such as intensive and semi-intensive, and other extensively managed large herds, depending on the agro-climatic regions in the country (Kothalawala 2011). Especially, the eastern province was selected as the area of study because of the high foot-and-mouth disease outbreak reported in the past (DAPH 2014). The dry zone covers two-third of the land area and around $75 \%$ of the total cattle and buffalo population (1.4 million) of the country. The study area of the eastern province consists of approximately one-fifth of cattle and buffalo population (DCS 2018). There are two established livestock management systems in the dry zone, namely, the traditional management system (extensive system) in the villages and the semi-intensive or intensive system. In the traditional system, the farm's size tends to be medium with an average of 18.2 animals per farm (Abeygunawardena et al. 1997) and large with an average of 64.2 animals per farm (DAPH 2009). Small herds of 6.6 animals per farm were kept semi-intensively or intensively. Livestock is the primary or most secondary incomegenerating source for the majority $(91.4 \%)$ of farmers in the traditional system and $51.5 \%$ in irrigated settlements (Abeygunawardena et al. 1997).

Ampara district of the dry zone was selected for this study because of the presence of different socio-cultural backgrounds with different livestock management systems, in addition to the high disease incidence (Wickramasuriya et al. 1983). The district of Ampara is in the southeast region of Sri Lanka and belongs to the eastern province. The total cattle and buffalo population in the Ampara district is approximately 90,000 (DCS 2018). The government veterinary range is the smallest functional unit of the veterinary delivery system and consists of the number of villages.

There was a huge outbreak of FMD in all 25 districts during the period from January to December in 2014, and officially reported FMD cases of 68,296 led to 1995 animal deaths due to this disease in Sri Lanka. Out of 20 ranges, 16 veterinary ranges of Ampara district were affected by FMD in the year 2014 and reported 4727 cases and 105 deaths (DAPH 2014). Kalmunai (KAL), Navithanveli (NAV), and Samanthurai (SAM) ranges were devastated by FMD (Fig. 1); therefore, these three areas were considered for the study. The ethnicity of these ranges was mainly Muslims and Tamils who engaged in livestock farming, and their main language was Tamil. The total number of registered livestock farms, including cattle, buffalo, and small ruminants, was 34,988 in the Ampara district. The number of registered livestock farms in KAL, NAV, and SAM was 3057, 3714, and 4207, respectively, in 2019. This information has been derived from the relevant veterinary offices and district office data. The livestock farm registration program was initiated in 2008. The basic data on livestock farms include cattle, buffalo, and small ruminants collected at the divisional veterinary range. This program continues to register newly established livestock farms. 


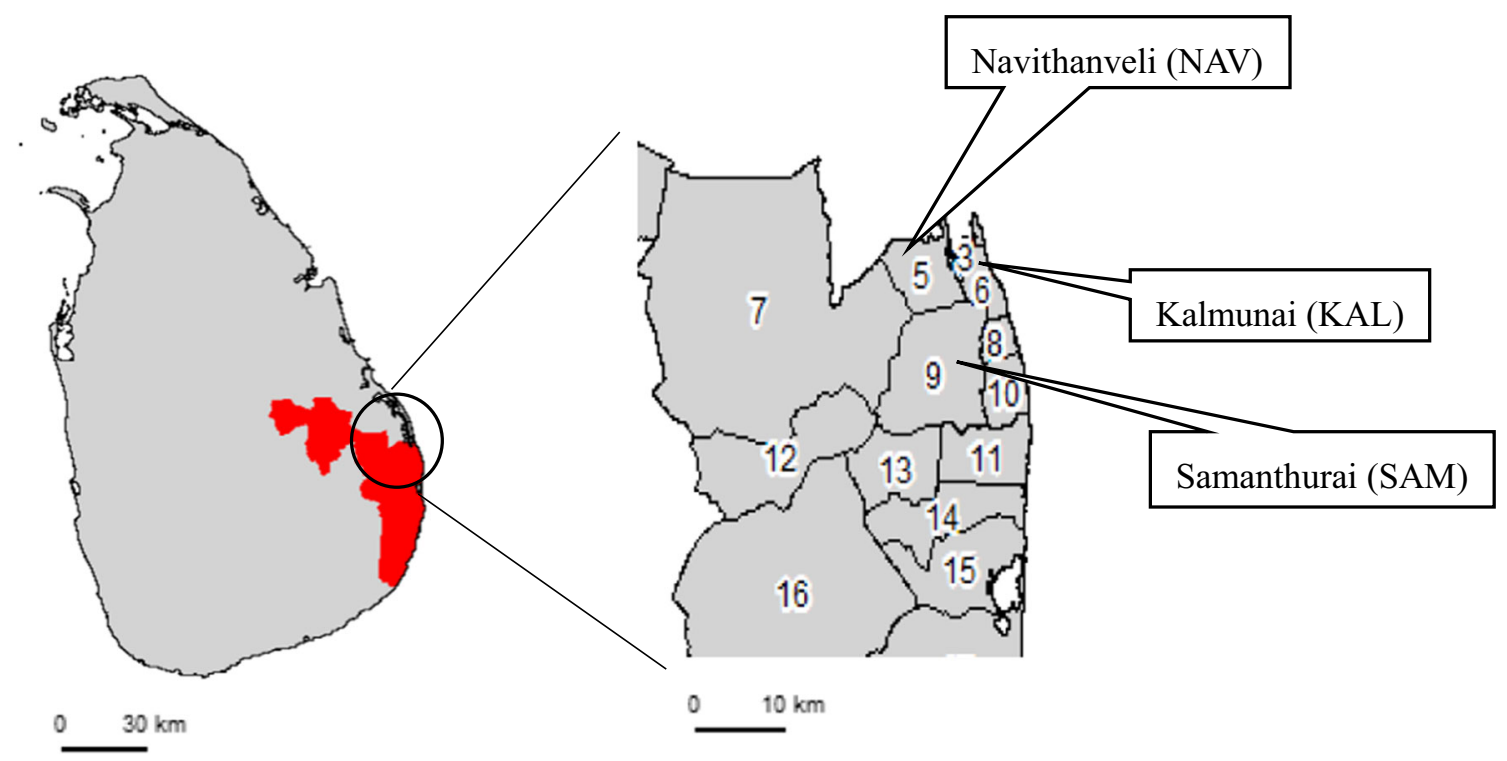

Fig. 1 Map of the study area: administrative divisions of the Ampara district in the eastern province of Sri Lanka

\section{Sample size and data collection}

The list of farm registrations available at the government veterinary office was used as the sampling frame, and farmers were randomly selected from 3 ranges in equal proportions of 60 samples. Random sampling was used to select 180 respondents for the study. This study was conducted among smalland large-scale livestock farmers who maintained cattle and buffaloes. Cattle owners were selected from three veterinary ranges. The study was conducted for a period of 1 month in September and October 2019. Data was collected from farmers through a questionnaire on rearing cattle and buffalo, which took approximately $20 \mathrm{~min}$ per interview by "face-toface" survey in their own language (Tamil). This questionnaire was used to collect all the required information for the purpose of the study. The questions concentrated mainly on social factors, farm factors, training programs, FMD vaccination, FMD outbreak, and the number of animals vaccinated for FMD.

\section{Data analysis}

The data collected from the study were imported and analyzed using the statistical software STATA 15. The tobit regression model was used for the animal-level vaccination coverage, and a probit regression model was used for participation in vaccination. The tobit model allows regression where the dependent variable is censored data, meaning that a substantial fraction of the observations on the dependent variable take a limited value. The probit model is a type of regression where the dependent variable can take only two $(1$ or 0$)$ alternatives (Damodar 2015). To analyze the score for FMD, knowledge and hygiene management practices-related questions were considered. Eight questions for clinical signs of FMD, disease transmission, and age of vaccination were included to evaluate knowledge on FMD (Table 2). To determine the score for knowledge, true, false, and do not know answers were given. A correct answer was given one mark, and incorrect and did not know answers were considered zero. Five basic hygiene management questions were asked to estimate the score of farm practices, for which yes/no answers were given as responses. The main social and farm factors of mean and standard deviation are summarized in descriptive statistics (Table 1).

\section{Results}

\section{Vaccination coverage, social, and farm factors}

In the field survey, cattle owners in the NAV range had a higher tendency to participate in vaccination than the other two ranges, KAL and SAM. The animal-level vaccination coverage in the three study areas was less than $60.0 \%$ (Fig. 2). In all three ranges, the gender of the farmers was mostly male $(88.3 \%)$, and approximately 10 to $15 \%$ were female. The ethnicity of farmers in KAL and SAM was mainly Muslims and Tamils $(66.7 \%)$ in NAV. The average age of farmers, who were mainly parental, was $47 ; 38.9 \%$ of farmers achieved formal education. The main source of income for farmers was agriculture, private jobs, and livestock. On an average, $25.6 \%$ of livestock farmers engaged in private jobs, such as fishing, business, and labor work in building construction in the KAL range $(41.7 \%)$. The results showed that very few farmers attended the farmer training program $(23.9 \%)$ conducted by veterinary offices. In the SAM range, majority of 
Table 1 Summary and descriptive statistics of the main social and farm characteristics of the sample

\begin{tabular}{|c|c|c|c|c|c|c|}
\hline Variable & Category & Mean & SD & KAL & NAV & SAM \\
\hline \multicolumn{7}{|l|}{ Social factors } \\
\hline Age of head farmer & Continuous data & 46.9 & 12.10 & 49.8 & 44.2 & 46.7 \\
\hline Gender of head farmer & 1: male; 0 : female & 88.3 & 0.32 & 90.0 & 85.0 & 90.0 \\
\hline Ethnicity & 1: Muslim; 0: Tamil & 62.2 & 0.48 & 63.3 & 33.3 & 90.0 \\
\hline Range & 1: NAV; 0: other & 33.3 & 0.47 & 33.3 & 33.3 & 33.3 \\
\hline Education & 1: formal; 0 : other & 38.9 & 0.48 & 31.7 & 53.3 & 31.7 \\
\hline Income source & 1: private; 0 : other & 25.6 & 0.43 & 41.7 & 21.7 & 13.7 \\
\hline Farmer training & 1: joined; $0:$ did not join & 23.9 & 0.42 & 36.7 & 26.7 & 8.3 \\
\hline \multicolumn{7}{|l|}{ Farm factors } \\
\hline Number of animals & Continuous data & 18.8 & 28.65 & 11.7 & 16.7 & 25.0 \\
\hline Farming experience & $1:>5$ years; $0:<5$ years & 73.3 & 0.44 & 78.3 & 58.3 & 83.3 \\
\hline Farm type & 1: extensive; 0 : other & 20.6 & 0.40 & 1.7 & 5.0 & 55.0 \\
\hline Knowledge FMD score & Continuous data & 54.5 & 2.14 & 62.9 & 48.3 & 52.3 \\
\hline Hygiene management score & Continuous data & 49.2 & 1.47 & 36.0 & 73.0 & 38.7 \\
\hline
\end{tabular}

Knowledge FMD score derived from the correct answer of the eight questions regarding FMD (Table 2). Hygiene management score derived from correct answers for five questions (Table 3)

the farmers had more than 5-year experience in livestock farming than KAL and NAV; therefore, it was considered that they were prioritizing their experience in farming leading to a lower tendency to participate in farmer training program (8.3\%). The type of farm system was semi-intensive, but in the SAM range, $55.0 \%$ of farms were managed under extensive livestock systems (Table 1).

\section{Knowledge of FMD and hygiene management practices}

Table 2 describes the level of knowledge on FMD. Most of the farmers correctly answered the questions about FMD symptoms, such as reduced milk production $(68.3 \%)$, animal lameness $(82.2 \%)$, salivation $(80.6 \%)$, and blisters in the mouth

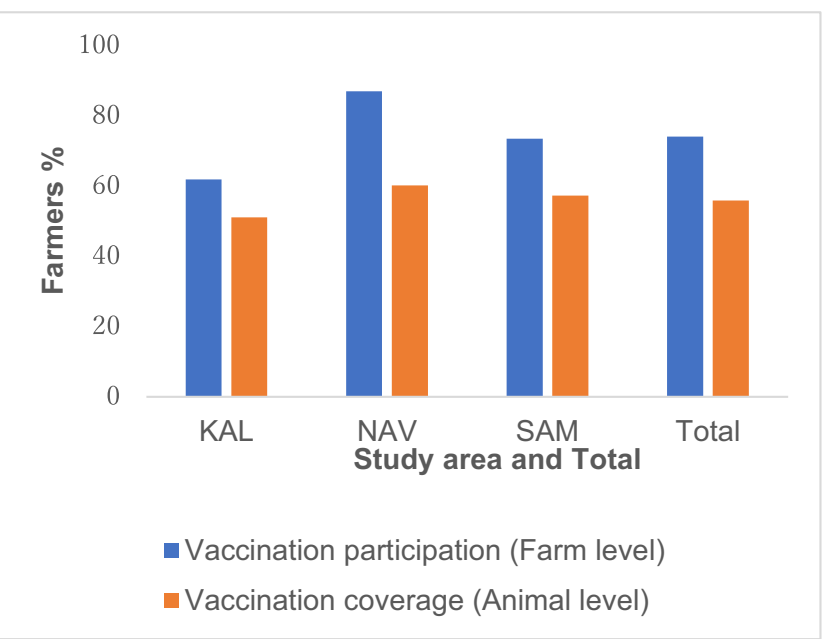

Fig. 2 Farmers' vaccination behavior on vaccination participation (farm level) and vaccination coverage (animal level) in 2018
(62.2\%). Only $47.8 \%$ of farmers believed that the FMD did not transmit from animal to human; most were not able to answer this question. Only $26.1 \%$ of farmers correctly answered to disease transmission by air and the age of first vaccination not at 1 year. This revealed poor knowledge of the mode of disease transmission and the age of vaccination. The mean knowledge of FMD and hygiene management score of 180 farmers was $54.5 \%$ and $49.2 \%$, respectively (Table 1). In the NAV range, most farmers followed basic hygiene management practices, such as wearing boots or slippers when working, using detergents for personal cleaning after work, and separating sick animals from healthy animals $(86.7 \%$, $95.0 \%$, and $75.0 \%$, respectively). However, most farmers had poor intentions to implement hygiene practices (Table 3).

In Table 4, the knowledge explained by social factors were the age of head of farmer, gender, ethnicity, range, education, and income source and those who had joined the farmer training program. We observed that male farmers and farmers with formal education positively influenced knowledge on FMD $(p<0.01)$. However, ethnicity and the income source of farmers did not influence the gain of knowledge. The effect of attending the training program in livestock management was significantly important to improve knowledge on FMD $(p<0.01)$.

\section{Factors affecting FMD vaccination behavior}

Table 5 shows the FMD vaccination behavior described in the level of participation of farmers in the FMD vaccination program, and vaccination coverage was calculated as the number of animals vaccinated against the number of animals in the herd. To describe the vaccination behavior, probit and tobit 
Table 2 Farmers' knowledge of FMD in three ranges

\begin{tabular}{llll}
\hline & $\begin{array}{l}\text { KAL } \\
(n=60)\end{array}$ & $\begin{array}{l}\text { NAV } \\
(n=60)\end{array}$ & $\begin{array}{l}\text { SAM } \\
(\mathrm{n}=60)\end{array}$ \\
\hline Reducing milk production (Yes) & 65.0 & 55.0 & 85.0 \\
$(n=180)$
\end{tabular}

Figures are presented in percentage of the total. (Yes)/(No) next to the relevant questions above are considered correct answers

models were used. The higher number of dairy farmers in NAV range received a government subsidy to alleviate poverty (Samurdhi program) due to low income. They were keen on the health of cattle for their livelihood; therefore, NAV range was significant to vaccination behavior $(p<0.05)$ than other two ranges. Regarding farm factors, the number of livestock and farming experience of more than 5 years was positively significant $(p<0.05)$. In addition, farmers performed basic hygiene management practices and also contributed to the vaccination programs $(p<0.1)$. At the animal level, vaccination coverage in cattle and buffalo farms was significant to farming experience and knowledge FMD score $(p<0.05)$. In this study, the FMD score and hygiene management score encouraged the vaccination behavior.

\section{Discussion}

The vaccination participation and coverage were recorded in NAV range as $86.7 \%$ and $60.0 \%$, respectively, higher than the other two ranges (Fig. 2). The hygiene management score was significantly higher in NAV (73.0\%) than in KAL and SAM, but knowledge FMD score in NAV was only $48.3 \%$. On average, the majority of farmers knew the clinical signs of lameness and salivation to identify the FMD from other diseases of cattle, but had poor awareness of the mode of transmission and age of vaccination, which are important factors in controlling FMD among endemic areas. The hygiene management practices were exhibited by the farmers at a relatively lower level (Table 3). This result was indicated together with knowledge FMD and hygiene management score as important factors to motivate farmers to facilitate both participation in vaccination and animal-level vaccination coverage.

Our results showed that knowledge FMD and hygiene management scores are obviously important to encourage farmers to participate in FMD vaccination behavior at the compulsory vaccination implemented by the Department of Animal Production and Health (DAPH). In traditional dairy farming systems, cattle and buffalo are owned and managed by men and women, but the majority were men who played an important role in disease prevention and control.

The total number of cattle and buffaloes in the farm also facilitates participation in FMD vaccination. If the farms have a higher number of animals, they tend to be vaccinated as protection from the outbreak of FMD. These farmers knew about the impact and economic loss due to FMD in the Ampara district. Some family members are hereditarily involved in livestock family farming as the main source of income. Farming experience was more significant for determining vaccination behavior. They were committed to taking care of the health of animals from the FMD outbreak.

Farmers' income, if mainly from private jobs, did not consider vaccinating the animal for FMD because they were too involved with any type of job, such as business, self-

Table 3 Hygiene management practices in three ranges

\begin{tabular}{llll}
\hline & $\begin{array}{l}\text { KAL } \\
(n=60)\end{array}$ & $\begin{array}{l}\text { NAV } \\
(n=60)\end{array}$ & $\begin{array}{l}\text { SAM } \\
(n=60)\end{array}$ \\
\hline Use boots or slippers & 33.3 & 86.7 & 45.0 \\
$(n=180)$
\end{tabular}

Figures are presented in percentage of the total 
Table 4 Social factors influencing on knowledge FMD score (tobit model)

\begin{tabular}{lllll}
\hline Variable & Coef. & SE & $z$ & $p$ value \\
\hline & & & & \\
$\quad$ Social factors & & & & \\
Age of head farmer & 0.030 & 0.012 & 2.39 & $0.017^{* * *}$ \\
Gender & 1.394 & 0.460 & 3.03 & $0.002^{* * *}$ \\
Ethnicity & -0.434 & 0.345 & -1.26 & 0.209 \\
Range & -0.975 & 0.349 & -2.79 & $0.005^{* * * *}$ \\
Education & 0.879 & 0.320 & 2.74 & $0.006^{* * *}$ \\
Income source & -0.067 & 0.344 & -0.20 & 0.845 \\
Farmer training & 1.053 & 0.349 & 3.02 & $0.003^{* * *}$ \\
Constant & 1.715 & 0.784 & 2.19 & 0.029 \\
\hline
\end{tabular}

$* *$ and $* * *$ denote statistical significance at the $5 \%$ and $1 \%$ level, respectively

Number of observations $=180, \log$ likelihood $=-375.071$, Prob. $>$ $\operatorname{chi}^{2}=0.000$

employment, fishing, building work, and carpentry work. They were busy with their work. This group of livestock farmers was not interested and reluctant to take care of animal health. This type of farmer should be given more focus to educate the importance of the spread of FMD and protecting other neighboring farm animals. Livestock farmers in the KAL range were more involved in private jobs for their main income source than other study areas. Livestock is not the main income source in the KAL range, which is located in the Kalmunai municipality area. The farmers were busy in their private work; therefore, the farm- and animal-level vaccination percentages were less than the other two ranges. Several socio-farm factors were identified as influencing the participation in vaccination and coverage such as range, main income source, number of animals in their farm, farming experience, type of management, knowledge of FMD, and hygiene management practices.

Farmers missed the opportunity to vaccinate all animals in their herd during the vaccination period due to the livestock farming system being mainly extensive and semi-intensive. Some farmers moved their animals from one range to another for feeding in uncultivated land or in the jungle area. Animal movement is an important concern in FMD spread from one range to another or district to district. To avoid this situation, prior planning and coordination with farmers is essential to vaccinate all suitable animals. The vaccination campaign should be supervised and monitored by veterinary surgeons in their assigned areas. Most of the animals are indigenous breeds and difficult to control during administration of the FMD vaccine in large herd extensive systems. Suitable animal restraint should be considered to ensure safe handling of animals and vaccinators during vaccination programs.

Effective communication between farmers and veterinary surgeons could play an important role in achieving optimization of vaccination strategies (Hall and Wapenaar 2012). The veterinary surgeon's role is significant in promoting awareness of a need to vaccinate, and an improved veterinary

Table 5 Social and farm factors affecting FMD vaccination behavior

\begin{tabular}{|c|c|c|c|c|c|c|c|c|}
\hline \multicolumn{5}{|l|}{$\begin{array}{l}\text { Vaccination participation (probit) } \\
\text { (farm level) }\end{array}$} & \multicolumn{4}{|c|}{$\begin{array}{l}\text { Vaccination coverage (tobit) } \\
\text { (animal level) }\end{array}$} \\
\hline Variable & Coef. & SE & $z$ & $p$ value & Coef. & SE & $z$ & $p$ value \\
\hline \multicolumn{9}{|l|}{ Social factors } \\
\hline Age of head farmer & 0.001 & 0.011 & 0.08 & 0.934 & -0.004 & 0.208 & -0.02 & 0.986 \\
\hline Gender & -0.231 & 0.372 & -0.62 & 0.535 & -3.696 & 7.380 & -0.50 & 0.617 \\
\hline Ethnicity & 0.091 & 0.292 & 0.31 & 0.755 & -2.654 & 5.352 & -0.50 & 0.620 \\
\hline Range & 0.966 & 0.384 & 2.51 & $0.012 * *$ & 14.916 & 6.613 & 2.26 & $0.024 * *$ \\
\hline Education & 0.447 & 0.274 & 1.63 & 0.103 & 4.383 & 4.998 & 0.88 & 0.381 \\
\hline Income source & -0.502 & 0.274 & -1.83 & $0.067^{*}$ & -3.278 & 5.487 & -0.60 & 0.550 \\
\hline Farmer training & 0.309 & 0.314 & 0.98 & 0.326 & 6.274 & 5.470 & 1.15 & 0.251 \\
\hline \multicolumn{9}{|l|}{ Farm factors } \\
\hline Number of animals & 0.022 & 0.011 & 2.05 & $0.040 * *$ & 0.109 & 0.091 & 1.19 & 0.233 \\
\hline Farming experience & 0.686 & 0.305 & 2.25 & $0.024 * *$ & 12.597 & 5.750 & 2.19 & $0.028 * *$ \\
\hline Farm type & 0.238 & 0.368 & 0.65 & 0.517 & 12.732 & 6.511 & 1.96 & $0.051 *$ \\
\hline Knowledge FMD score & 0.132 & 0.062 & 2.13 & $0.033 * *$ & 2.841 & 1.183 & 2.40 & $0.016 * *$ \\
\hline Hygiene management score & 0.195 & 0.108 & 1.81 & $0.070^{*}$ & 3.282 & 2.006 & 1.64 & 0.102 \\
\hline Constant & -1.398 & 0.696 & -2.01 & 0.045 & 10.783 & 12.875 & 0.84 & 0.402 \\
\hline
\end{tabular}

$*$ and $* *$ denote statistical significance at the $10 \%$ and $5 \%$ level, respectively. Number of observations $=180$. For probit regression, log likelihood $=$

-74.741 , Prob. $>$ chi $^{2}=0.000$ and for Tobit regression, log likelihood $=-864.207$, Prob. $>$ chi $^{2}=0.000$ 
surgeon-farmer relationship enhances the performance to accept the vaccination. To improve farmers' knowledge of FMD and basic hygiene management practices, livestock educational training programs are an important tool to control the FMD outbreak in this study area. The acceptance of vaccination by farmers will mostly depend on the level of awareness of vaccination and improvement in their knowledge of FMD by capacity building of farmers on FMD control.

The present farmer training mainly focused on producing milk value addition, poultry management, cattle and poultry feed formulation and pasture, fodder cultivation, and cattle and goat management. Therefore, this study clearly showed that the importance, identification, mode of transmission of FMD, vaccination, and hygiene management practices of livestock farms should be considered. Some farmers believed that the FMD vaccine caused abortion in any period of pregnancy, reduced milk production, and weakened the animal. Farmers believed that FMD did not cause death to cattle and buffaloes and could be treated by antibiotics, not by the FMD vaccine; few farmers even treated the FMD-affected animal by traditional methods in rural areas. The use of antibiotics during FMD outbreaks was reported in other developing countries (Nampanya et al. 2016; Young et al. 2017). Misperception about the FMD vaccine should be eliminated among farmers to accept the vaccination. Prioritizing and organizing regular training programs accommodating rural farmers is a must (Rezvanfar 2007).

For the control of the FMD outbreak, farmers should be aware of the economic importance of the FMD. Currently, in the eastern province, a mass vaccination program is being implemented by the DAPH. To maintain the herd immunity for FMD, regular vaccination intervals are essential for the strategic control program of the World Organisation for Animal Health (OIE), and following the steps of PCP-FMD is important to eradicate the disease in Sri Lanka (FAO 2018b). This study revealed that to achieve adequate vaccination coverage, farmers' knowledge and hygiene management practices needed to be identified for successful FMD control programs. That the disease control authority and policymakers should consider addressing these issues is an important finding of this research.

\section{Conclusion}

FMD is regularly reported every year among small and large herd traditional dairy farms in the eastern province of Sri Lanka. Farmers' knowledge of FMD and hygiene management practices were linked with participation in vaccination and vaccination coverage in this area. There is a need to educate farmers on the impact of FMD and associated control measures, including vaccination and hygiene management in farmer training awareness programs. Farm factors of having a higher number of animals, farming experience of more than 5 years, knowledge on FMD, and hygiene management practices contributed to significant enhancement in participation in vaccination and vaccination coverage. Animal health extension strategies should be properly organized, and the current data management system of cattle and buffaloes should be improved in each range to enable more reliable determination of vaccination coverage for control of FMD in high-risk areas in Sri Lanka.

Acknowledgments The authors would like to acknowledge the Japanese government for funding this research. The Obihiro University of Agriculture and Veterinary Medicine in Hokkaido, Japan, is highly respected. The Department of Animal Production and Health, Sri Lanka, is acknowledged for the assistance extended in the research. Special thanks to Dr. M.A.M. Fazi, provincial director, DAPH, eastern province, Sri Lanka, for their cooperation and assistance extended in the field data collection. Finally, we would like to extend our thanks to all farmers, veterinary surgeons, and livestock development officers for their cooperation.

\section{Compliance with ethical standards}

This manuscript does not contain any clinical studies or patient data.

Conflict of interest The authors declare that they have no conflict of interest.

\section{References}

Abeygunawardena, H. A., Rathnayaka, D. and Jayathilaka, W. M. A. P., 1997. Characteristics of cattle farming systems in Sri Lanka. Journal of National Science Foundation of Sri Lanka, 25(1), 25-38.

Damodar, G., 2015 Econometrics. $2^{\text {nd }}$ Ed. Palgrave 170-227.

DAPH, 2009. Estimation of cost of production of milk in different agro climatic zones of Sri Lanka. Department of Animal Production and Health, Peradeniya Sri Lanka. http://daph.gov.lk.

DAPH, 2014. Annual report, Department of Animal Production and Health., Peradeniya (Sri Lanka). http://daph.gov.lk.

DAPH, 2019. Annual report, Department of Animal Production and Health., Peradeniya (Sri Lanka). http://daph.gov.lk

DCS, 2018. Department of Census and Statistics, Agriculture and environmental statistic division., Colombo, Sri Lanka, accessed in http:// www.statistics.gov.1k/agriculture/1ivestock/ livestockpopulationsubnational.htmt.

Dernburg, A. R., Fabre, J., Philippe, S., Sulpice, P. and Calavas, D., 2007. A study of the knowledge, attitudes, and behaviors of the French dairy farmers toward the farm register. Journal of Dairy Science, 90(4), 1767-1774.

FAO, 2012. The Progressive Control Pathway for FMD control (PCPFMD). Principles, Stages description Sans standard, Rome.

FAO, 2018a. The Progressive Control Pathway for FMD control (PCPFMD). http://www.fao.org/eufmd/global-situation/pcp-fmd/en/pdf.

FAO, 2018b. The Global Foot and Mouth Disease control strategy. http:// www.fao.org/ag/againfo/programmes/en/empres/disease_fmd.asp, pdf.

Fernando, W. W. H. S., 1969. FMD in Ceylon, Part 1 history, epizootiology, and economic losses. Ceylon Veterinary Journal, (XVII)3, 43-58.

Goswami, A. and Sagar, R. L., 1996. Development of cognitive learning scale to test the knowledge of livestock owners about vaccination 
against contagious diseases. Journal Veterinary Animal Science, 27, 32-37.

Gunasekera, I. and Fernando, W. W. H. S., 1980. Introduction and spread of foot and mouth disease virus type $\mathrm{C}$ in Sri Lanka. Ceylon Veterinary Journal, 51-54.

Hall, J. and Wapenaar, W., 2012. Opinions and practices of veterinarians and dairy farmers towards herd health management in the UK. Veterinary record, 170.

Knight-Jones, T. J. D. and Rushton, J., 2013. The Economic impacts of foot and mouth disease- what are they, how big are they and what do they occur? Preventive Veterinary Medicine, 112, 161-173.

Kodituwakku, S.N., 2000. Diagnosis and control of foot and mouth disease in Sri Lanka using ELISA- based technologies. inis.iaea.org, 123-129.

Kothalawala, K.A.C.H.A., 2011. Milk production under different management systems in Sri Lanka an economic perspective. Sri Lanka Veterinary Journal, 58(B), 29.

Martin, S. W., Dietrich, R. A., Genho, P., Heuschle, W. P., Jones, R. L. and Koller, M., 1994. Epidemiologic/Economic Tuberculosis Studies and Bioeconomic Research considerations. In N. A. press, ed. Livestock Disease Eradication: Evaluation of the Cooperative State-Federal Bovine Tuberculosis Eradication Program.

Nampanya, S., Khounsy, S., Abila, R., Young, J. R., Bush, R. D. and Windsor, P.A., 2016. Financial impacts of foot-and-mouth disease at village and national levels in Lao PDR. Transboundary and Emergency Disease, 63 (5), e403-e411.

OIE (2019). https://www.oie.int/en/animal-health-in-the-world/animaldiseases/Foot-and-mouth-disease.

Rezvanfar, A., 2007. Communication and socio-personal factors influencing adoption of dairy farming technologies amongst livestock farmers. Livestock Research for Rural Development, 19 (3), 33.

Rushton, J., 2009. The Economics of Animal health and production. Oxfordshire, UK: CAK International.

Saini, S. S., Sharma, J. K. and Kwatra, S.M., 1992. Assessment of some factors affecting the prevalence of foot and mouth disease among the traditionally managed animal population of Punjab state. Socioeconomic and animal health-related interests. Indian Journal of Animal Science, 62 (1), 1-4.

Sturgess, G. W., 1900. Report of the Government Veterinary Surgeon, Ceylon Administration Report.

Wickramasuriya, U. G. J. S., Peiris, G. S., Kendaragama, K. M. T. and W. M. Karunadasa., 1983. A survey on the incidence of bovine brucellosis in three districts of Sri Lanka. Sri Lanka Veterinary Journal, 31, 27-31.

Winsdor, P. A., 2011. Perspectives on the Australian animal health aid projects in South-East Asia. Transboundary and emerging diseases, 58 (5), 375-386.

Winsdor, P. A., Freeman, P. G., Abila, R., Benigno, C., Nim, V. and Cameron, A., 2011. Control and eradication of Foot and mouth disease in the Bicol surveillance buffer zone in the Philippines. Transboundary and emerging diseases, 58, 421-433.

Young, J R., Suon, S., Olma, L., Bun, C., Hok, C., Ashley, K., Bush, R.D. and Winsdor, P. A., 2017. Investigation of smallholder farmer biosecurity and implications for sustainable foot and mouth disease control in Cambodia. Transboundary and Emerging Disease, 64 (6), 2000-2012.

Publisher's note Springer Nature remains neutral with regard to jurisdictional claims in published maps and institutional affiliations. 